\title{
CRYPTOCURRENCIES (BITCOINS) IN FINANCIAL REPORTING - NEW CHALLENGE FOR ACCOUNTANTS
}

\section{Marlene Gröblacher}

Undergraduate student, Advantage Austria, Embassy of Austria, Austria
Correspondence:

Marlene Gröblacher

e-mail:

\begin{abstract}
:
As the exchange and trade with cryptocurrencies is steadily rising, consequently, they become subject to financial reporting. The essence of financial reporting derives from the objective to provide stakeholders of an enterprise with sustainable information about the financial well-being of the business. Accountants might face complications meeting the objective of financial reporting considering cryptocurrencies such as Bitcoins due to the absence of guidelines in both, IFRS and US GAAP. In the first part, this paper applies the existing IAS and IFRS guidelines to this practical issue and contributes to the process by which diversification in practice can be avoided. Broadly speaking, the problem can be addressed by classifying Bitcoins as intangible assets. Whereas, Bitcoins fail the definition of cash, cash equivalents, financial instruments, as well as the definition of inventory. In the second part, a discussion concerning non-financial reporting of Bitcoins can be found.
\end{abstract}

Keywords:

cryptocurrency, classification, financial reporting, intangible assets, non-financial reporting

\section{INTRODUCTION}

Bitcoin is a digital currency and is often referred to as cryptocurrency. It is the "world's first completely decentralized cryptocurrency" (J. Brito, \& A. Castillo, 2018). Recognizing the special aspect of Bitcoins takes an in-depth look at the founding principle, which is the usage of cryptography to control the transfer of money without depending on central authorities (Bitcoin Wiki, 2018). Corresponding to the official website of Bitcoin, one of the first steps in acquiring Bitcoins is to set up a digital wallet, on your smartphone or computer. After setting up your digital wallet you automatically receive an individual private and public key to maintain a secure exchange within the market of Bitcoins, as these keys function as a signature. After completing these steps, the mining of Bitcoins can begin, which is simply the process of updating the public ledger (Bitcoin, 2018). Bitcoins can also be purchased for a certain amount of money. The Bitcoin system is built as a peer-to-peer network. Expressed in other words, this means that there is no central authority issuing new money or tracking transactions, since this is achieved by the means of the network collectively. As a Bitcoin is transferred from user A to user B, user A adds the public key of user B to the Bitcoin. Now user B is the owner of the Bitcoin and can either keep it or transfer it to another user. At the same time, user A is not able to send the already issued Bitcoin to another user because a public ledger of all previous transactions is collectively maintained by the network. Prior to each transaction, the validity of a Bitcoin is checked (Mahr, 2013). The reason that prevents the Bitcoin from being spent twice is called blockchain. Each transaction bears a small fee that is credited to the user that is maintaining records in the general ledger on the network (Mahr, 2013). It could also be said that the blockchain is a public registry that stores transactions in a network and is replicated on every computer that uses it, which makes the transactions forgery-proof. 
The amount of Bitcoins that can exist is limited to 21 million; as a result, their value can be increased due to the fact that Bitcoins are scarce resources. Supply will run out at one moment, it is estimated that this will happen in the year 2140 (Bitcoin Wiki, 2018). At the beginning of the first paper as of 22 February 2018 "the total number of bitcoins that have already been mined (...)" (Blockchain, 2018) was $16,878,938$, close to the end of the second paper as of 6 July 2018 the number increased to 17,133,013. This indicates a growing market.

Due to the fact that there are no guidelines in neither IAS nor IFRS until this point, this paper is a result of a systematic review of the existing IAS and IFRS guidelines compared to the essence of Bitcoins. This review paper furthermore represents an extension of a previous article of the author written together with Ph.D Marina Protic (M. Protić, \& M. Groeblacher, 2018). Also, further literature was used from other papers focusing on Bitcoins, as well as a few reliable online sources from well-known companies such as E\&Y. Additionally, a study from Citrix on Bitcoins (2018) and the EU Directive (2014/95/EU) on non-financial reporting have been examined. However, Bitcoins have rarely been studied directly in terms of financial reporting. In accordance with (Citrix, 2018), it can be noted that a great number of German companies is in the possession of Bitcoins. 500 IT- decision makers participated in this study, all from companies with more than 250 employees. Still, it was not possible to find out which companies are in concern. Several publications released in recent years documented the rise and fall of Bitcoin in terms of exchange rates and market capitalization. To this date, Bitcoins remain the cryptocurrency with the largest market capitalization next to more than one hundred other cryptocurrencies (Coin Ranking, 2018).

\section{CERTAIN ISSUES OF BITCOIN CLASSIFICATION IN ACCOUNTING}

Now that the critical building blocks concerning the Bitcoin are settled, the next question is what Bitcoins represent in terms of accounting and how accountants can classify Bitcoins that are held by an enterprise.

\section{Bitcoin $\neq$ Cash}

"Cash comprises cash on hand and demand deposits" (IAS 7 (6), 2018). Both terms are not applicable to Bitcoins. As cryptocurrencies are not issued or backed by any government or state, the value of it completely underlies the demand and the supply of the market. And due to its new concept, there are huge fluctuations in the value of Bitcoins, as it is illustrated in the chart below (Bit/€) we can notice huge fluctuations, especially from the beginning of the year 2012 until the year 2014, an increase from $10 €$ up to $500 €+$ can be arbitrated. Additionally, compared to its starting value of a few euros and today's value of $10,000 €$, which is an additional indicator for its great fluctuations.

Figure 1. This figure represents the value of Bitcoins expressed in $€$ for the time period from the end of the year 2011 to the beginning of 2018(Ariva, 2018)

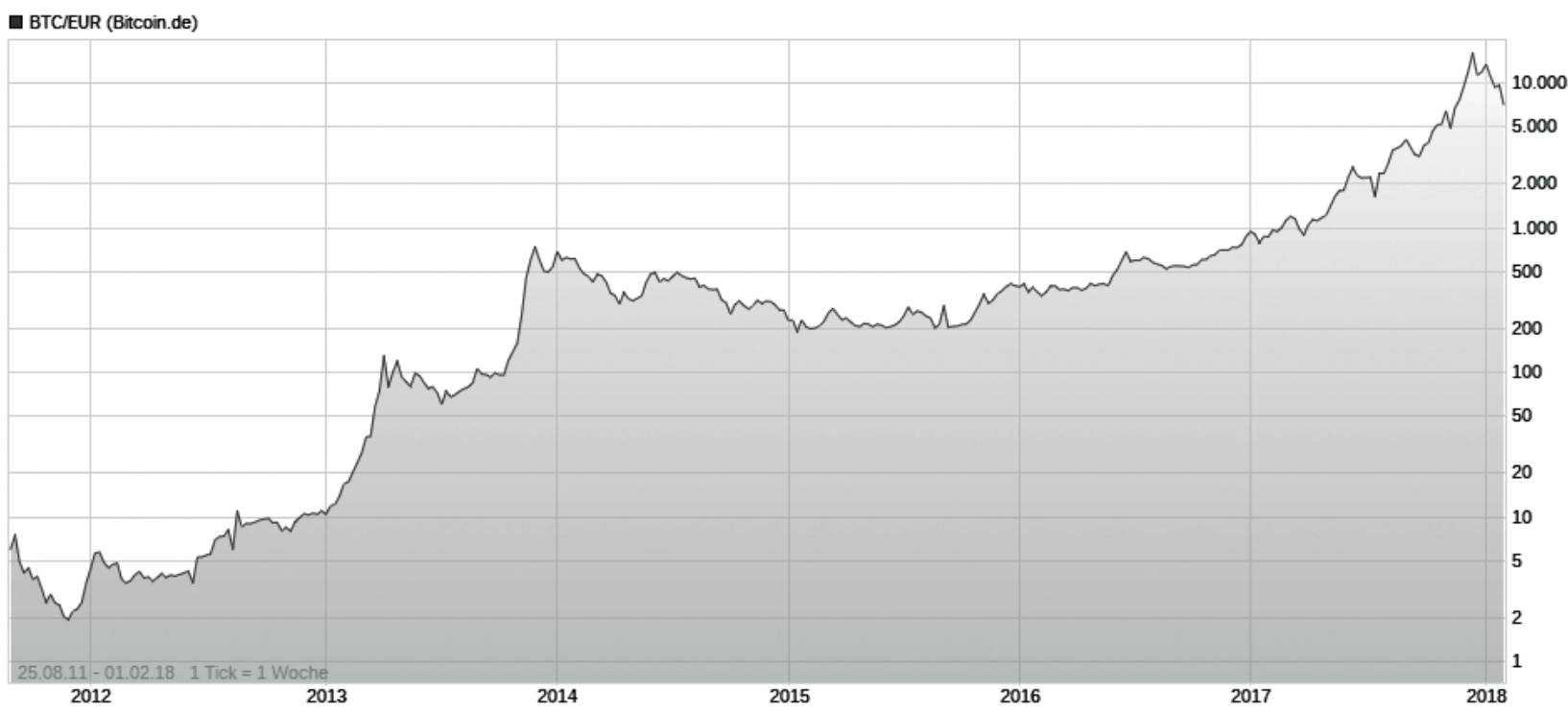


Bearing this in mind, we can conclude that in this case the cryptocurrency cannot be valued as cash or demand deposits since it does not meet the definition prescribed in IAS 7.

\section{Bitcoin $\neq$ cash equivalent}

As defined in IAS 7: "Cash equivalents are short-term, highly liquid investments that are readily convertible to known amounts of cash and which are subject to an insignificant risk of changes in value" (IAS 7 (6), 2018). Due to its new concept as a medium of exchange, there are huge fluctuations in the value of Bitcoins. In order to address comprehensively the significant fluctuations in its value, some dates have been extracted and illustrated in table 1 below.

Table 1. FX rates Bitcoun/€

\begin{tabular}{ccc}
\hline FX rate as of & Bitcoin & $€$ \\
\hline 1.11 .2011 & 1 & $2,44676 €$ \\
\hline 1.11 .2017 & 1 & $5.358,09 €$ \\
\hline
\end{tabular}

Source: (Oanda, 2018)

As illustrated in table 1 above the exchange rate as of $1^{\text {st }}$ November 2011 ( 1 Bitcoin $=2,44676 €)$ and the exchange rate as of $1^{\text {st }}$ November 2017 ( 1 Bitcoin $\left.=5.358,09 €\right)$, this demonstrates a great percentage change with an increase of $218887.15 \%$.

Another vivid example that stresses the enormous fluctuations that Bitcoins underlie is given next: FX as of $8^{\text {th }}$ January $2018(1$ Bitcoin $=13.878,9 €)$ and the FX as of $8^{\text {th }}$ February $2018(1$ Bitcoin $=6.397,87 €)($ Oanda, 2018) . This represents a decrease of $53.9 \%$ in just one month. This makes it nearly impossible to exchange Bitcoins for a known amount of cash.

With reference to, the above-given table and the previous example we can clearly determine that the changes in the value of Bitcoins are significantly high, construed accordingly we can clearly identify that Bitcoins hold a significant risk of changes in value within them and hence, the market of Bitcoins is a volatile market.

If one looks at the way Bitcoins acquire their value, we find that they obtain their intrinsic value due to its users, that exchange Bitcoins for goods or services. An important implication of these findings is that this market is growing, but is at the same time volatile, which contributes to the opinion that the Bitcoin is rather a speculation tool than a currency.

\section{Bitcoin $\neq$ financial instrument}

In Germany, Bitcoins have been classified as financial instruments in 2013. Meanwhile, this classification has been abolished again. Therefore, in the next step, the definition of a financial instrument is discussed and why it does not fit into the definition of Bitcoins. A definition for financial instruments is given by IAS 32 in which they are equal to "any contract that gives rise to a financial asset of one entity and a financial liability or equity instrument of another entity" (IAS 32: Financial Instruments Presentation, (11)). Bitcoins itself do not bear any contractual right to receive a good, service, cash or anything else. Although this is self-explanatory, it must be pinpointed that a Bitcoin can be in neither case a liability or equity instrument. Another counter-argument preventing the classification of Bitcoins as a financial instrument is the fact that in the first place they fail the definition of financial assets (IAS 32 (11), 2018). As indicated in the previous section 2.1 Bitcoins cannot be classified as cash. Neither, are they an equity instrument of another party nor do they represent a contract. Hence, the conclusion here is that it is impossible to classify Bitcoins as a financial asset. As they do fail this definition they cannot be taken further into consideration of representing a financial instrument since one of the pre-defined requirements is the classification as a financial asset.

\section{Bitcoin $\neq$ inventory}

According to the scope section of IAS 2: Inventories do not exclude intangible assets (IAS $2(2-5), 2018)$. But the assets that fall into the definition of inventory must be: „(a) held for sale in the ordinary course of business; (..)" (IAS 2 (6)). The reason why Bitcoins are most likely to fail the definition of inventory is that it is very improbable that Bitcoins represent the ordinary course of a business as they might not be traded consistently enough. Moreover, soon the process of trading and acquisition of Bitcoins will be affected due to new laws on money laundering where the scope will also include cryptocurrencies. This would then aggravate specific entities in performing their ordinary course of business.

\section{Bitcoin $=$ intangible asset}

IAS 38 prescribes that "an intangible asset is an identifiable non-monetary asset without physical substance. "(IAS 38 (8), 2018). The previous conclusion that Bitcoins do not meet the definition of cash, and even less possible is the obtaining of a fixed or determinable amount for it (see figure 1 and table 1). By taking into consideration the previous statement, as well as the fact that Bitcoins cannot be defined as financial assets nor have a physical 
substance, it can be said that the above definition of IAS 38 matches to Bitcoins. To justify this conclusion, the requirements that must be fulfilled for a non-monetary asset to be identifiable will be analyzed. In accordance with IAS 38 (12) "An asset is identifiable if it is either:

(a) is separable, i.e. is capable of being separated or divided from the entity and sold (...) regardless of whether the entity intends to do so;

(b) arises from contractual or other legal rights, regardless of whether those rights are transferable or separable from the entity or from other rights and obligations." (IAS 38 (12), 2018).

It is possible to separate Bitcoins from the entity and to sell them or to exchange them individually. In a word, the first part of this definition is applicable to Bitcoins. Point (b) is not applicable to Bitcoins. Considering that, only one point of the two has to be applicable it can be said that Bitcoins also fulfill this area of the definition. Back to the roots of accounting and the framework of financial reporting, an entity has to have future economic benefits from an asset, as well as control over it (IAS 38 (8), 2018). Pursuant to IAS 38 (13), it is possible for an entity to have control over an asset and future economic benefits arising from it even in the absence of legal enforceability, as an alternative the entity may be able to find another way to control the future economic benefits (IAS 38 (13), 2018).

Concerning the determination of the useful life of an intangible asset $\mathrm{E} \& \mathrm{Y}$ gives a greater insight, stating that in if there no law, regulation or contract and further factors constrain the useful life of an intangible asset it shall be treated as indefinite (E\&Y, 2018).

According to IAS 38, assets with indefinite useful life are not subject to depreciation (IAS 38 (107), 2018).

Having outlined the main arguments, the conclusion is that in terms of accounting Bitcoins are no currency, but intangible assets with indefinite useful life and hence, are not subject to depreciation.

There is also, however, a further point to be considered the recognition of an intangible asset which is that it can only be recognized as an intangible asset if the entity can expect future economic benefits from it and that the costs can be measured reliably (IAS 38 (21), 2018).

In this case, the entity's management is responsible for the best possible estimation of the probability of future economic benefits by using reasonable and acceptable assumptions and evidence based on the overall economic conditions at the time of initial recognition.

IAS 38 (24) prescribes that an intangible asset shall be measured initially at cost (IAS 38 (24), 2018). As previously stated there are two ways of acquiring Bitcoins, buying and mining. When buying Bitcoins on a virtual market we exchange it for a certain amount of money, which represents the purchase value. When it comes down to acquirement through the mining process, the Bitcoin represents an internally generated intangible asset.

According to IAS 38 (51-53) difficulties arise in the process of recognition due to the question if and when the asset will constitute to the economic benefits, also sometimes it is not possible to distinguish the expenditures for the internal generation from the cost of maintaining. In this case the framework for the phase of research and development must be applied (IAS 38 (51-52), 2018). To determine whether such an asset can be recognized depends on whether the generation is categorized as research or development phase.

If the two phases cannot be distinguished from each other, the entity treats the incurred costs as if they emerged in the research phase. Intangible assets that originate from a research phase shall not be recognized. Conversely, intangible assets that arise from development can be recognized as assets if they meet the specific criteria prescribed by IAS 38 (53) - (57).

If we assume that the mining process does not imply the development phase, but only the research phase according to IAS 38, Bitcoins acquired through mining cannot be recognized as an asset, but all expenditures made for the purpose of its acquisition are recognized as the expense of the period.

However, if the mining process can meet the requirements of the development phase as required by IAS 38 (57), then their value is recognized as one of the intangible assets.

Concerning the measurement as prescribed by IAS 38 (74-75) after initial recognition, an intangible asset shall be measured either with the cost model or revaluation value (IAS 38 (74-75), 2018).

\section{NON- FINANCIAL REPORTING AND BITCOINS - BRIEF DIGRESSION}

In the past century, not only the financial sustainability of an entity became crucial but also the reputation in terms of the following examples such as human rights and appropriate taxation.

The recently issued EU Directive, which was published in 2014, on non-financial reporting aims to improve transparency by providing stakeholders with relevant, useful as well as comparable non-financial information about social impacts and risks related to environmental matters, social and employee aspects, respect of human rights, anti-corruption and anti-bribery issues as well as diversity in their board of directors. This EU Directive is applicable since 2017 throughout the EU. 
Entities within European Union member states that have more than 500 employees, $20 €$ million balance sheet total or $40 €$ million revenue are required to disclose information on non-financial performances from 2018 onward. Besides, entities not incorporated within this scope may issue these reports (European Commission, 2018).

Even though Bitcoins are making the headlines in recent times due to their wide fluctuations in value, they also make it to the headlines of the press due to criminal misuses, such as money laundering, tax evasion, and illicit trade. As Bitcoins become more and more popular the hacker attacks are also increasing.

This becomes a very critical issue, especially for people who have been mining Bitcoins from the beginning on, the effect of that is that millions of dollars in Bitcoins can be stolen using only phone numbers, without any chance for reimbursement (Forbes, 2018).

Such weaknesses in the Bitcoin network, respectively in its security may have an impact on the overall reputation of companies holding Bitcoins. For this reason, it is advisable to implement the disclosure of non-financial reports as a practice to inform the stakeholders about reasons for holding cryptocurrency and its use, as well as policies regarding risk management. It can be seen from the previous analysis that, the market of Bitcoins is volatile and hence, could result in a huge loss in profit for the entity itself and consequently its stakeholders, concerning this matter the risk management policies are of crucial importance for stakeholders.

Currently, large companies that accept Bitcoins as a means of payment such as Microsoft (Microsoft Support, 2018) do not disclose any information about this event nor the accounting and taxation treatment of these in their notes to the financial statements.

Apart from the above mentioned, as the now applicable EU Directive is also concerned with environmental matters and many mining entities are establishing their business in countries where the costs of electricity are relatively low, the environmental impact that the mining of Bitcoins is causing must be scrutinized.

A very recent study evaluates the environmental impact more specifically with possible solutions such as fiscal policy instruments, environmental taxes and regulations that can constrain certain countries from mining more Bitcoins depending on whether the source of energy that is used is renewable or not, as well as the devices used for it (Truby, 2018).

Whilst the discussion in the preceding paragraph, a recent study, reveals that German companies do not hold digital currency anymore just for the case of a hacker attack with possible ransom in form of the virtual currency, but also because a lot of them are planning to use the cryptocurrency to pay providers, employees or trade them and use the smart contract function of the blockchain. The study was already conducted in August 2017 once. Anyhow, the reserve in average slightly increased from 24 to 27 Bitcoins. (Citrix, 2018).

As mentioned in the previous section, the companies are planning to expand the use of their digital currencies in form of payment for employees or providers. This approach seems to lead in the right direction since the use of Bitcoins is limited compared to other assets, which can be rented or leased, when an entity is not able or willing to use it in their course of business.

\section{CONCLUSION}

Considering, the basic functions of currency Bitcoins are exempted from this definition. As Bitcoins, cannot create price stability, nor serve as a unit of account or as a legal mean of payment, they cannot be defined as currency.

All things considered, the conclusion is that in terms of accounting Bitcoins are no currency, but intangible assets with indefinite useful life and hence, are not subject to depreciation.

In order to rectify the problem of the measurement, purchase value is applicable if the Bitcoin was acquired on a virtual market and fair value for the subsequent measurement also in case of mining.

As the exchange and trade with cryptocurrencies are steadily rising another accounting guidance in IFRS or US GAAP will be needed to avoid diversification in practice. This new standard should also allocate essential information to prevent wrong interpretation. In the meantime, accountants should disclose precisely how they classify and measure the cryptocurrency in the notes to the financial statements.

Considering the findings from the above sections, nonfinancial reporting especially in terms of the risk management for companies that hold Bitcoins and the environmental impact that Bitcoin mining companies are causing, it will most likely become of crucial importance to disclose non-financial information in behalf of the overall reputation and in the interest of investors, as well as other stakeholders.

\section{LITERATURE}

Ariva. (2018, 2 1). Ariva. Retrieved from Bitcoin Kurs in Euro Chart: http://www.ariva.de/btc-eur-bitcoin-euro-kurs/ chart

Bitcoin Wiki. (2018, 2 22). Bitcoin Wiki. Retrieved from Controlled Supply: https://en.bitcoin.it/wiki/Controlled_supply 
Bitcoin Wiki. (2018, 7 22). Bitcoin Wiki. Retrieved from Bitcoin Wiki: https://en.bitcoin.it/wiki/Main_Page

Blockchain. (2018, 7 22). Blockchain. Retrieved from Bitcoins in circulation: https://blockchain.info/de/charts/totalbitcoins

Blockchain. (2018, 7 22). Blockchain. Retrieved from Blockchain Info: https://blockchain.info/de/charts/total-bitcoins

Citrix. (2018, 3 6). Citrix. Retrieved from Infografik Bitcoins und Kryptowährung in deutschen Unternehmen: https://www.citrix.com/content/dam/citrix/en_us/ documents/news/citrix-infografik-bitcoins-final-de.pdf

Coin Ranking. (2018, 09 21). CoinRanking. Retrieved from Coin Ranking - Cryptocurrency prices at a glance: https://coinranking.com/

E\&Y. (2018, 2 23). EY. Retrieved from Financial Reporting Developments: Intangibles - Goodwill and others - EY: https://www.ey.com/publication/vwluassetsdld/financia lreportingdevelopments_bb1499_intangibles_22june 2018/\$file/financialreportingdevelopments_bb1499_ intangibles_22june2018.pdf

European Comission. (2018, 7 17). Europa. Retrieved from Guidelines on non-financial reporting (methodology for reporting non-financial information): https://ec.europa. eu/anti-trafficking/sites/antitrafficking/files/guidelines_ on_non-financial_reporting.pdf

Forbes. (2018, 2 22). Retrieved from Hackers Have Stolen Millions Of Dollars In Bitcoin -- Using Only Phone Numbers: https://www.forbes.com/sites/laurashin/2016/12/20/ hackers-have-stolen-millions-of-dollars-in-bitcoin-using-only-phone-numbers/\#7ddf51b738ba

IAS 2 (2-5). (2018). IFRS. Retrieved from IAS 2: Inventories: http://eifrs.ifrs.org/eifrs/bnstandards/en/IAS2.pdf

IAS 2 (6). (n.d.). IFRS. Retrieved from IAS 2: Inventories: http://eifrs.ifrs.org/eifrs/bnstandards/en/IAS2.pdf

IAS 32 (11). (2018, 2 21). IFRS. Retrieved from IAS 32: Financial Instruments Presentation: http://eifrs.ifrs.org/eifrs/ bnstandards/en/IAS32.pdf

IAS 38 (107). (2018, 2 23). IFRS. Retrieved from IAS 38: Intangible Assets: http://eifrs.ifrs.org/eifrs/bnstandards/ en/IAS38.pdf

IAS 38 (12). (2018, 2 23). IFRS. Retrieved from IAS 38: Intangible Assets: http://eifrs.ifrs.org/eifrs/bnstandards/ en/IAS38.pdf

IAS 38 (13). (2018, 2 23). IFRS. Retrieved from IAS 38: Intangible Assets: http://eifrs.ifrs.org/eifrs/bnstandards/ en/IAS38.pdf
IAS 38 (21). (2018, 2 23). IFRS. Retrieved from IAS 38: Intangible Assets: http://eifrs.ifrs.org/eifrs/bnstandards/ en/IAS38.pdf

IAS 38 (24). (2018, 2 24). IFRS. Retrieved from IAS 38: Intangible Assets: http://eifrs.ifrs.org/eifrs/bnstandards/ en/IAS38.pdf

IAS 38 (51-52). (2018, 2 24). IFRS. Retrieved from IAS 38: Intangible Assets: http://eifrs.ifrs.org/eifrs/bnstandards/ en/IAS38.pdf

IAS 38 (53). (2018, 2 24). IFRS. Retrieved from IAS 38: Intangible Assets: http://eifrs.ifrs.org/eifrs/bnstandards/ en/IAS38.pdf

IAS 38 (74-75). (2018, 2 25). IFRS. Retrieved from IAS 38: Intangible Assets: http://eifrs.ifrs.org/eifrs/bnstandards/ en/IAS38.pdf

IAS 38 (8). (2018, 2 23). IFRS. Retrieved from IAS 38: Intangible Assets: http://eifrs.ifrs.org/eifrs/bnstandards/en/ IAS38.pdf

IAS 7 (6). (2018, 2 22). IFRS. Retrieved from IAS 7: http://eifrs. ifrs.org/eifrs/bnstandards/en/IAS7.pdf

J.Brito, \& A. Castillo. (2018, 2 1). BITCOIN A Primer for Policymakers. Retrieved from Mercatus Center: https://www. mercatus.org/system/files/Brito_BitcoinPrimer.pdf

M. Protić, \& M. Groeblacher. (2018, May). DILEME U VEZI SA PRIZNAVANJEM I VREDNOVANJEM KRIPTO VALUTA (BITKOINA) USLED NEDOSTATKA ZAKONSKE REGULATIVE. Poresko-računovodstveni instruktor (No. 187), 79- 87.

Mahr, J. (2013, 12 2). Die kriminelle Nutzung von virtuellen Währungen bzw. Kryptowährungen zum Zwecke der Steuerhinterziehung, Geldwäsche und sonstigen Straftaten sowie dessen Bedeutung für die Strafverfolgungsbehörden. Fachhochschule Wiener Neustadt, pp. 26,29 .

Microsoft Support. (2018, 7 17). Microsoft Support. Retrieved from Add money to your Microsoft account with Bitcoin: https://support.microsoft.com/en-us/help/13942/ microsoft-account-add-money-with-bitcoin

Oanda. (2018, 22 2). Oanda. Retrieved from Währungsrechner Devisenkurse: https://www.oanda.com/lang/de/currency/converter/

Truby, J. (2018). Decarbonizing Bitcoin: Law and policy choices for reducing the energy consumption of Blockchain technologies and digital currencies. Energy Research \& Social Science, 44, 399-410.

Wiki, B. (2018, 222). Bitcoin Wiki. Retrieved from Controlled Supply: https://en.bitcoin.it/wiki/Controlled_supply 